\title{
EFEKTIVITAS INSEKTISIDA EMAMEKTIN BENZOAT TERHADAP HAMA Plutella xylostella L. DAN HASIL TANAMAN SAWI PUTIH (Brassica pekinensis) DI LAPANGAN
}

\author{
Oleh: \\ Sri Nur W Lestariningsih*) \\ Edy Sofyadi*) \\ Toni Gunawan*) \\ email: srinurwid@gmail.com.
}

\begin{abstract}
Abstrak
Tujuan dari penelitian ini adalah untuk mendaptkan konsentrasi yang efektif dari insektisida dengan bahan aktif Emamektin benzoate dalam mengendalikan ulat Plutella xylostella dan menghasilkan tanaman sawi putih yang tinggi.

Percobaan dilakukan di desa Wangunharja, Kecamatan Lembang, Kabupaten Bandung Barat yang berlangsung dari bulan Oktober sampai Desember 2018. Percobaan menggunakan Rancangan Acak Kelompok dengan 5 perlakuan dan 5 ulangan. Perlakuan konsentrasi insektisida yang diaplikasikan yaitu $\mathrm{A}=0 \mathrm{ml} / \mathrm{l}, \mathrm{B}=$ Bestfast $250 \mathrm{EC}$ dengan konsentrasi $2 \mathrm{ml} / \mathrm{l}, \mathrm{C}=$ Siklon 5,7 WG dengan konsentrasi $0,1 \mathrm{~g} / \mathrm{l}, \mathrm{D}=$ Siklon 5,7 WG dengan konsentrasi $0,3 \mathrm{~g} / \mathrm{l}$, dan $\mathrm{E}=$ Siklon 5,7 WG dengan konsentrasi $0,5 \mathrm{~g} / \mathrm{l}$. Pengamatan yang diukur adalah intensitas serangan dan bobot bersih sawi putih.

Hasil penelitian menunjukkan insektisida dengan bahan aktif Emamektin benzoat dengan dengan konsentrasi 0,3 g/l (D) dan 0,5 g/l (E) efektif untuk pengendalian hama ulat Plutella xylostella dan menghasilkan sawi putih yang tinggi di lapangan.
\end{abstract}

Kata kunci : Efektivitas, Emamektin benzoat, Plutella xylostella, Sawi putih.

\begin{abstract}
The research aimed to obtain of effective concentration an insecticide with the active ingredient Emamectin benzoate in controlling the Plutella xylostella and high yield of chinese cabbage in the field.

The experiment was conducted in the village of Wangunbarja, Lembang Subdistrict, West Bandung Regency, which lasted from October to December 2018. The experiment used a randomized block design with 5 treatments and 5 replications. The insecticide concentration treatments is $A=0 \mathrm{ml} / \mathrm{l}, B=$ Bestfast 250 EC with concentrations of $2 \mathrm{ml} / \mathrm{l}, \mathrm{C}=$ Cyclone $5.7 \mathrm{WG}$ with a concentration of $0.1 \mathrm{~g} / \mathrm{l}, \mathrm{D}=$ Cyclone $5.7 \mathrm{WG}$ with a concentration of $0,3 \mathrm{~g} / \mathrm{l}$, and $E=C y c l o n e ~ 5.7 \mathrm{WG}$ with a concentration of $0.5 \mathrm{~g} / \mathrm{l}$. Observations measured were attack intensity and net weight of chinese cabbage.

The results showed that the insecticide with the active ingredient Emamectin benroate with concentrations of $0.3 \mathrm{~g} / \mathrm{l}$ (D) and $0.5 \mathrm{~g} / \mathrm{l}$ (E) was effective for controlling Plutella xylostella and high yield of chinese cabbage in the field.
\end{abstract}

Keywords: Effectiveness, Emamectin Benzoate, Plutella xylostella, Chinese cabbage.

*)Mahasiswa Program Studi Agroteknologi Fakultas Pertanian UICM. **)Staf Dosen Program Studi Agroteknologi Fakultas Pertanian UICM. 


\section{PENDAHULUAN}

Sawi putih di Indonesia dikenal dengan nama petsai, kubis cina atau sawi jantung. Dalam bahasa Inggris disebut Chinese Cabbage dan bahasa Prancis disebut Chou de Chine. Di Indonesia, petsai berkembang di Cipanas, Lembang, Pangalengan, Malang dan Tosari, bahkan sekarang telah berkembang ke Jawa Barat, Jawa Tengah, Jawa Timur, Bengkulu, Sumatra Utara, Lampung, Bali, Nusa Tenggara Timur, Timor-Timur, Kalimantan Barat, Kalimantan Timur, Sulawesi Utara, Sulawesi Selatan, Irian Jaya dan Maluku (Simanjuntak, 1994). Produksi sawi/petsai di Indonesia pada tahun 2013 sekitar 635.728 ton, sementara itu produksi mengalami penurunan pada tahun 2016 dengan produksi mencapai 601.200 ton dengan rata - rata hasil per hektar 9.92 ton (Badan Pusat Statistik Indonesia, 2016). Hal ini sangat jauh dari pada potensi hasil yang mungkin didapat untuk tanaman sawi putih yaitu sebesar 30 -35 ton $/ \mathrm{Ha}$

Salah satu kendala dalam budidaya tanaman sawi putih adalah gangguan ulat Plutella xylostella yang menyerang tanaman sawi putih; yang umumnya juga menyerang tanaman keluarga kubiskubisan. Apabila tidak dikendalikan akan mengakibatkan kerusakan pada tanaman dengan timbulnya lubang pada daun dan dapat berujung pada kematian tanaman tersebut. Pengendalian hama ini menjadi perhatian khusus para petani karena dampaknya yang sangat besar bagi petani dan bisa menjadikan kerugian ekonomi apabila tidak ditangani dengan serius. Untuk itu pengendalian hama harus diperhatikan dan dilakukan dengan terpadu dengan memperhatikan aspek ekonomis dan efektifitas dalam mengendalikan hama sehingga tidak menimbulkan kerugian yang amat besar bagi petani. Dalam percobaan pendahuluan, tanaman sawi putih di lahan tempat percobaan mengalami gangguan serangan hama ulat daun kubis denga intensitas serangan sebesar 7 persen.

EFEKTIVITAS INSEKTISIDA EMAMEKTIN BENZOAT TERHADAP HAMA Plutella xylostella L. DAN HASIL TANAMAN SAWI PUTIH (Brassica pekinensis)

DI LAPANGAN
Ulat daun kubis (Plutella xylostella L., Lepidoptera: Plutellidae) adalah hama utama yang sangat merusak tanaman Brassicaceae, terutama kubis, sawi, dan caisin di Indonesia (Winasa dan Herlinda, 2003). Larva P. xylostella menyerang tanaman yang masih muda di persemaian maupun tanamana yang ada di lapangan. Kerusakan oleh hama ini dapat mencapai $100 \%$ apabila tidak segera dikendalikan (Kalshoven, 1981).

Untuk menanggulangi kemungkinan kerugian akibat dari serangan hama $P$. xylostella pada tanaman sawi putih perlu dilakukan pencegahan ataupun pengendalian hama supaya tidak menimbulkan kerugian ekonomis bagi petani. Upaya pengendalian hama $P$. xylostella yang menyerang bisa dilakukan dengan penggunaan insektisida. Akan tetapi, P. xylostella dilaporkan telah resisten terhadap beberapa jenis insektisida, seperti senyawa fosfat organik, dan piretroid sintetik (Moekasan et al., 2004). adalah ulat Plutella xylostela dari daerah Lembang, Pangalengan, Kejajar Dieng dan Batu sudah sangat resisten pada insektisida jenis deltrametrin dan profenofos sedangankan untuk insektisida jenis abamektin sudah agak resisten di daerah Kejajar Dieng dan Batu (Moekasan dkk., 2004). Beberapa tahun juga di laporkan bahwa ulat $P$. xylostella di daerah Lembang, Pangalengan, Garut dan Buleleng sudah sangat resisten pada insektisida jenis deltrametrin dan profenofos namun masih cukup rentan terhadap spinosad (Udiarto dan Setiawati, 2007). Salah satu insektisida alternatif yang dapat digunakan untuk pengendalian hama $P$. xylostella adalah yang mengandung bahan aktif emamektin beñoat.

Di daerah Garut dilaporkan bahwa ulat Plutella xylostella sudah tidak rentan terhadap insektisida jenis deltametrin, klorantraniliprol dan profenofos walapun sudah di lakukan aplikasi melebihi dosis yang di anjurkan, tetapi masih rentan terhadap Emamektin benzoat dan spinetoram sekalipun dengan aplikasi dengan dosis rendah dari anjuran (Cardi, 2014). Insektisida dengan bahan aktif Emamektin

SRI NUR WIDYASTUTI, EDY SOFYADI dan TONI GUNAWAN 
benzoat adalah insektisida racun kontak berbentuk butiran yang dapat didispersikan dalam air. Konsentrasi yang di anjurkan untuk hama Liriomyza chinetic pada bawang merah adalah $0.1 \mathrm{~g} / 1$ sedangkan untuk kutu daun Myzus persicae pada tanaman cabai dan Helicoverpa armigera adalah $0.3 \mathrm{~g} / 1$ ( PT. Nufarm Indonsia, 2016 ).

Dalam beberapa musim tanam belakangan ini, penggunaan insektisida dengan bahan aktif Emamektin benzoat sudah mulai digunakan hal ini tidak lepas dari sudah mulai resistennya hama khususnya Plutella xylostella terhadap insektisida dengan bahan aktif yang lain. Salah satu jenis insektisida dengan bahan aktif Emamektin benroat yang ada di pasaran saat ini adalah Siklon 5,7 WG dengan konsentrasi penggunaan yang sangat rendah yaitu $0,1 \mathrm{~g} / 1$ air menjadikan insektisida ini relatif tidak mengeluarkan banyak biaya pengedalian hama.

\section{METODE PENELITIAN}

\section{Tempat dan Waktu Penelitian}

Penelitian dilakukan di kebun percobaan yang berlokasi di desa
Wangunharja, Kecamatan Lembang, Kabupaten Bandung Barat. Penelitian berlangsung dari bulan Oktober sampai dengan Desember 2018.

\section{Alat dan Bahan Percobaan}

Alat yang di gunakan adalah : Cangkul, Handsprayer, Ember, Sendok dan Timbangan elektrik. Bahan yang di gunakan adalah : Benih sawi putih Pupuk kandang, pupuk NPK 16-16-16, Polybag, Siklon 5,7 WG dan Bestfast 250 EC.

\section{Metode Penelitian}

Metode penelitian yang digunakan adalah percobaan. Rancangan yang digunakan adalah Rancangan Acak Kelompok dengan 5 perlakuan dan setiap perlakuan terdiri dari 5 ulangan seluruh plot percobaan ada 25 plot dan tiap-tiap plot terdiri dari 5 polybag, jumlah tanaman yang digunakan sebanyak 125 tanaman. Perlakuan konsentrasi insektisida yang diaplikasikan dapat dilihat pada Tabel 1.

Table 1. Perlakuan Konsentrasi Insektisida yang Diaplikasikan.

\begin{tabular}{cl}
\hline Perlakuan & \multicolumn{1}{c}{ Konsentrasi yang digunakan } \\
\hline A & Tanpa adanya penyemprotan insektisida \\
B & Penyemprotan dengan menggunakan Bestfast 250 EC dengan konsentrasi $2 \mathrm{ml} / 1$ \\
$\mathrm{C}$ & Penyemprotan dengan menggunakan Siklon 5,7 WG dengan konsentrasi $0,1 \mathrm{~g} / 1$ \\
$\mathrm{D}$ & Penyemprotan dengan menggunakan Siklon 5,7 WG dengan konsentrasi $0,3 \mathrm{~g} / 1$ \\
$\mathrm{E}$ & Penyemprotan dengan menggunakan Siklon 5,7 WG dengan konsentrasi 0,5 \\
\hline
\end{tabular}

Pengamatan

Pengamatan Penunjang

Pengamatan penunjang ini meliputi pengamatan tanaman dari gangguan penyakit serta dari gangguan hama lain dan juga mengamati suhu dan kelembaban di lokasi percobaan.

\section{Pengamatan Utama}

Pengamatan utama meliputi:

1. Intensitas serangan
Variable yang diamati adalah kategori skala kerusakan pada daun/ tanaman yang didasarkan pada pengamatan secara kualitatif yang selanjutnya di buat nilai skala (scoring). Angka scoring ini akan digunakan untuk menghitung intensitas serangan hama Plutella xylostella melalui rumus sebagai berikut:

$$
I S=\frac{\sum(n \times v) \times 100 \times \%}{Z \times N}
$$

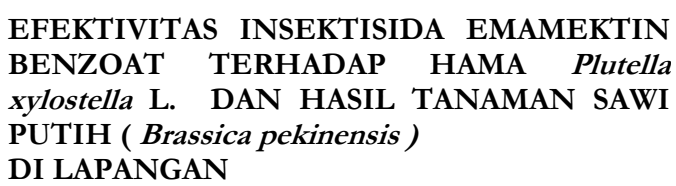


Keterangan :

IS = Intensitas Serangan;

$\mathrm{n}$ : jumlah daun rusak tiap kategori serangan;

$\mathrm{v}$ : nilai skala tiap kategori serangan;

$Z$ : nilai skala tertinggi kategori serangan;

$\mathrm{N}$ : jumlah daun yang diamati

Sedangkan nilai skala yang digunakan, dikategorikan sebagai berikut :

$0=$ Tidak terdapat kerusakan pada daun

$1=$ Terdapat kerusakan dari $0-20 \%$

$3=$ Terdapat kerusakan dari $20-40 \%$

$5=$ Terdapat kerusakan dari $40-60 \%$

$7=$ Terdapat kerusakan dari $60-80 \%$

$9=$ Terdapat kerusakan lebih dari $80 \%$

2. Menghitung bobot bersih hasil panen pada umur 65 hari setelah tanam.

\section{Pelaksanaan Percobaan}

Pelaksanaan percobaan di lakukan dengan cara melakukan penanaman dan pemeliharaaan pada tanaman sawi putih serta mengamati gangguan serangan hama ulat Plutella, yaitu sebagai berikut:

1. Penyemaian dilakukan pada sebuah naungan yang sebelumnya sudah disiapkan media berupa campuran tanah dan pupuk kandang yang sudah di ayak dan di siram, kemudian benih di semai dan ditutup menggunakan dedaunan. Setelah 7 hari benih yang sudah memiliki 2 helai daun kemudian di pindahkan ke kokeran yang terbuat dari daun pisang dan di pelihara selama kurang lebih 7 hari untuk kemudian di tanam.

2. Penanaman di lakukan setelah bibit memiliki 2-3 helai daun sejati dan sudah berusia kurang lebih 14 hari, penanaman dilakukan pada media polybag yang sudah di siapkan dan di isi oleh pupuk kandang dan tanah dengan perbandingan 2:1, antar polybag di beri jarak $50 \mathrm{~cm}$.

3. Penyiraman di lakukan pada pagi hari dan di lakukan setiap hari apabila tidak terjadi hujan. Penyiraman di lakukan sampai tanaman siap panen

4. Penyulaman adalah mengganti tanaman yang mati dengan tanaman

EFEKTIVITAS INSEKTISIDA EMAMEKTIN BENZOAT TERHADAP HAMA Plutella xylostella L. DAN HASIL TANAMAN SAWI PUTIH (Brassica pekinensis)

DI LAPANGAN baru. Penyulaman dilakukan pada 7 HST.

5. Pemupukan susulan di lakukan dua kali pada saat tanaman berumur 14 HST dan 28 HST dengan menggunakan pupuk NPK 16-16-16 , aplikasi pemupukan susulan ini di lakukan dengan cara di larutkan dengan air, yaitu melarutkan $1 \mathrm{~kg}$ NPK 16-16-16 dengan 100 liter air dan di aplikasikan dengan cara di kocor sebanyak $250 \mathrm{ml}$ setiap tanaman.

6. Penyemprotan insektisida dengan bahan aktif Emamektin benzoat, di lakukan setelah tanaman berusia 7 HST dan di lakukan penyemprotan setiap 7 hari sampai panen.

7. Pemanenan, pemanenan dilakukan pada saat tanaman berumur antara 6575 HST.

\section{HASIL DAN PEMBAHASAN}

\section{Pengamatan Penunjang}

Pada saat pengamatan di lapangan tanaman sawi putih yang di tanam tidak hanya terserang oleh hama Plutella xylostella saja, namun juga mengalami gangguan serangan dari hama siput (Helix pomatia) kemudian terdapat serangan penyakit berupa akar gada (Plasmodiophora brassicae wor.) dan bercak kuning atau Downy mildew yang di akibatkan oleh jamur Pseudoperonospora cubensis. Serangan dari hama dan penyakit tersebut relatif sangat rendah di bawah 10\% dari populasi tanam dan semua serangan tersebut dapat dikendalikan, dimana untuk pengendalian hama siput (Helix pomatia) dikendalikan dengan cara membersihkan tanaman yang terdapat siput tersebut dengan memunguti satu persatu kemudian untuk pengendalian tanaman yang terserang akar gada dengan cara penyulaman atau diganti dengan tanaman baru dan untuk pengendalian tanaman yang terkena bercak kuning dengan membersihkan daun yang sudah terserang.

Cuaca yang terjadi pada saat proses penelitian adalah pada saat peralihan dari musim kemarau menuju musim hujan dimana pada saat awal tanam masih 
musim kemarau kemudian di minggu kedua setelah tanaman terjadi curah hujan cukup tinggi dan lumayan sering dan hujan hampir terjadi setiap hari. Data rataan cuaca selama penelitian adalah sebagai berikut.

Tabel 2. Data suhu, kelembaban, dan curah hujan selama percobaan.

\begin{tabular}{lccc}
\hline \multirow{2}{*}{ Bulan } & \multicolumn{3}{c}{ Nilai rata - rata } \\
\cline { 2 - 4 } & Suhu ${ }^{\circ} \mathbf{C}$ & Kelembaban \% & Curah Hujan (mm) \\
\hline Oktober & 20.30 & 87.77 & 2.04 \\
November & 20.54 & 87.70 & 15.10 \\
Desember & 20.43 & 87.64 & 9.18 \\
\hline
\end{tabular}

Dari data yang didapat mengenai iklim yang terjadi selama penelitian sangat memungkinkan untuk pertumbuhan tanaman sawi putih dimana tanaman sawi putih dapat tumbuh pada suhu berkisar antara $15-20^{\circ} \mathrm{C}$ dan kelembaban yang sesuai untuk tanaman sawi putih berkisar antara 80 - 90\% serta curah hujan yang baik untuk sawi putih adalah 1000 - 1500 $\mathrm{mm} /$ tahun (Nurshanti, 2010).

Kondisi iklim selama percobaan juga sangat memungkinkan untuk ulat $P$. xylostella berkembang biak karena curah hujan pada saat penelitian masih rendah dan pada awal penelitian yaitu bulan Oktober merupakan waktu dimana populasi ulat $P$. xylostella sangat tinggi karena antara bulan April - Oktober atau pada musim kemarau adalah periode dimana populasi ulat $P$. xylostella sangat tinggi (Moekasan et. al., 2004).

\section{Pengamatan Utama \\ Intentsitas Serangan}

Intensitas serangan $P$. xylostella diamati dengan cara mengamati kerusakan pada daun sawi, pengamatan tersebut di lakukan selama enam kali pengamatan setelah aplikasi yaitu pada umur tanaman 12, 19, 26, 33, 40 dan 47 hari setelah tanam. Analisis statistik data pada intensitas serangan P. xylostella dari masing masing umur dapat dilihat pada Lampiran 3 sampai dengan Lampiran 8 secara berturut turut sesuai dengan umur pengamatan. Adapun hasil uji lanjutan dengan menggunakan Uji Jarak Berganda Duncan pada taraf 5\% disajikan pada disajikan pada Tabel 3.

Tabel 3. Presentase Kerusakan Daun Sawi Putih akibat Plutella xylostella.

\begin{tabular}{|c|c|c|c|c|c|c|}
\hline \multirow{2}{*}{ Perlakuan } & \multicolumn{6}{|c|}{ Persen kerusakan daun setelah aplikasi } \\
\hline & $\mathbf{I}$ & II & III & IV & $\mathbf{V}$ & VI \\
\hline & \multicolumn{6}{|c|}{...............persen ...................... } \\
\hline$A=$ kontrol & $0,92 \mathrm{a}$ & $12,03 \mathrm{c}$ & $17,29 \mathrm{~d}$ & $21,21 \mathrm{~d}$ & $24,52 \mathrm{~d}$ & $35,97 \mathrm{~d}$ \\
\hline $\mathrm{B}=$ Bestfast $250 \mathrm{EC} ; 2 \mathrm{ml} / 1$ & 0,79 a & $7,29 \mathrm{~b}$ & $10,80 \mathrm{c}$ & $13,46 \mathrm{c}$ & $15,10 \mathrm{c}$ & $17,77 \mathrm{c}$ \\
\hline $\mathrm{C}=$ Siklon 5,7 WG; 0,1 g/1 & 0,48 a & 2,38 a & $4,97 \mathrm{~b}$ & $7,03 \mathrm{~b}$ & $7,96 \mathrm{~b}$ & $9,99 \mathrm{~b}$ \\
\hline $\mathrm{D}=$ Siklon 5,7 WG; $0,3 \mathrm{~g} / \mathrm{l}$ & $0,53 \mathrm{a}$ & 1,46 a & 2,83 a & $4,72 \mathrm{a}$ & 5,52 a & 6,62 a \\
\hline $\mathrm{E}=$ Siklon 5,7 WG; 0,5 g/1 & 0,48 a & $1,52 \mathrm{a}$ & $2,40 \mathrm{a}$ & 4,79 a & 5,36 a & 5,92 a \\
\hline
\end{tabular}

Keterangan: Angka yang diikuti oleh huruf yang sama pada kolom yang sama menunjukkan berbeda tidak nyata pada Uji Jarak Berganda Duncan taraf 5\%.

Pada pengamatan pertama saat umur tanaman 12 Hari Setelah Tanam kerusakan daun sawi dari setiap perlakuan tidak berbeda nyata, perbedaan nyata baru terlihat pada saat aplikasi kedua atau pada saat umur tanaman 19 Hari Setalah Tanam. Dapat dilihat kerusakan daun pada perlakuan kontrol berbeda sangat nyata bila di bandingkan dengan perlakuan pembanding maupun dengan 
perlakuan menggunakan emamektin benzoat dengan dosis masing - masing $0,1 \mathrm{~g} / 1,0,3 \mathrm{~g} / 1 \mathrm{dan} 0,5 \mathrm{~g} / \mathrm{l}$.

Intensitas kerusakan daun sawi putih setelah aplikasi ke II, III, IV, V, dan VI menunjukan perbedaan yang nyata. Pada perlakuan emamektin benroate dengan dosis 0,3 g/l (D) dan 0,5 g/l (E), menunjukkan intensitas kerusakan daun sawi putih yang paling rendah dan berbeda nyata dengan perlakuan lainnya. Hal ini berati bahwa perlakuan emamektin benzoat dengan dosis $0,3 \mathrm{~g} / \mathrm{l}$ (D) dan 0,5 $\mathrm{g} / 1$ (E) efektif dalam menekan serangan ulat P. xylostella pada tanaman sawi putih. Intensitas serangan daun yang menggunakan perlakuan emamektin benzoat dengan dosis $0,3 \mathrm{~g} / \mathrm{l}$ (D) dan 0,5 $\mathrm{g} / \mathrm{l}$ (E) relatif rendah karena ulat $P$. xylostella yang menyerang tanaman sawi putih dapat dikendalikan. Hal tersebut menunjukkan bahwa menggunakan insektsida dengan bahan aktif emamektin benzoate menggunakan dosis sesuai anjuran cukup efektif mengendalikan serangan hama ulat P. xylostella (Aini, 2016).

\section{Bobot hasil panen Sawi Putih}

Analisis statistik data bobot bersih tanaman sawi putih dapat dilihat pada Lampiran 9. Adapun hasil uji lanjutannya dengan menggunakan Uji Jarak Berganda Duncan pada taaf $5 \%$ dapat dilihat pada Tabel 4.

Tabel 4. Berat Bersih sawi putih.

\begin{tabular}{|c|c|}
\hline Perlakuan & Bobot bersih (g) \\
\hline $\mathrm{A}=$ kontrol & $425,20 \quad \mathrm{a}$ \\
\hline $\mathrm{B}=$ Bestfast $250 \mathrm{EC} ; 2 \mathrm{ml} / 1$ & $1115,20 \mathrm{~b}$ \\
\hline $\mathrm{C}=$ Siklon 5,7 WG; $0,1 \mathrm{~g} / 1$ & $1306,00 \quad c$ \\
\hline $\mathrm{D}=$ Siklon 5,7 WG; 0,3 g/1 & $1662,00 \mathrm{~d}$ \\
\hline $\mathrm{E}=$ Siklon $5,7 \mathrm{WG} ; 0,5 \mathrm{~g} / 1$ & $1736,00 \mathrm{~d}$ \\
\hline
\end{tabular}

Pada Tabel 4 terlihat, penggunaan insektisida yang mengandung emamektin benzoat dengan konsentrasi 0,3 g/1 (D) dan $0,5 \mathrm{~g} / 1$ (E) menghasilkan bobot bersih tanaman sawi putih yang tinggi. Dimana hasil sawi putih yang didapat lebih tinggi bila di bandingkan dengan perlakuan pembanding maupun kontrol. Hal ini disebabkan serangan dari hama $P$. xylostella dapat ditekan sehingga intensitas kerusakan daun tanaman sawi putih paling rendah. Akibatnya berpengaruh terhadap bobot bersih hasil panen sawi putih. Pada perlakuan kontrol mengindikasikan bahwa kerusakan daun yang di akibatkan dari serangan hama $P$. xylostella dapat berdampak pada penurunan hasil yang didapatkan.

Hasil bobot bersih tanaman sawi putih yang tinggi di dapat dari tanaman yang tingkat serangan atau kerusakan yang rendah hal ini disebabkan karena tanaman yang intensintas serangannya rendah

EFEKTIVITAS INSEKTISIDA EMAMEKTIN BENZOAT TERHADAP HAMA Plutella xylostella L. DAN HASIL TANAMAN SAWI PUTIH ( Brassica pekinensis)

DI LAPANGAN memiliki tingkat kerusakan daun yang lebih rendah pula, hal tersebut berdampak pada proses fotosintesis yang lebih optimal sehingga menghasilkan bobot tanaman sawi yang lebih berat.

\section{KESIMPULAN}

1. Insektisida dengan bahan aktif Emamektin benzoat efektif dalam mengendalikan hama ulat Plutella xylostella dan hasil tanaman sawi putih.

2. Insektisida dengan bahan aktif Emamektin benroat dengan dengan konsentrasi 0,3 g/1 (D) dan 0,5 g/l (E) efektif untuk pengendalian hama ulat Plutella xylostella dan menghasilkan produksi sawi putih yang tinggi. dan TONI GUNAWAN 


\section{DAFTAR PUSTAKA}

Aini, Hilmi Arifatil. 2016, Toksisitas Enam Jenis Insektisida Komersial Terhadap Ulat Daun Kubis Plutella xylostella dari Kecamatan Pacet, Kabupaten Cianjur, Jawa Barat. Skripsi. Departemen Proteksi Tanaman. Fakultas Pertanian. Institut Pertanian Bogor.

Badan Pusat Statistik. 2016. Produksi Petsai (Sawi) Menurut Provinsi Tahun 2013-2016. Diakses 9 Mei 2018. https: / wmw.bps.go.id. Jakarta

Cardi, M. 2014. Kerentanan Plutella Xylostella Dari Garut, Jawa Barat Terhadap Lima Jenis Insektisida Komersial Dan Ekstrak Tephrosia vogelii. Skripsi. Departemen Proteksi Tanaman. Fakultas Pertanian. Institut Pertanian Bogor

Kalshoven, L. G. E., 1981. The Pest of Crops in Indonesia. Revised and Translated By P.A. Van der laan. Jakarta: PT. Ichtiar Baru-Van Hoeve.

Moekasan, T.K., S. Sastrosiswojo, T. Rukmana, H. Susanto, I.S. Purnamasari, A. Kurnia. 2004. Status Resistenis Lima Strain Plutella xylostella L. Terhadap
Formulasi Fipronil, Deltametrin, Profenofos, Abamektin dan Bacillus thuringiensis. J Hort. 14(2):84-90.

Nurshanti, D.F. 2010. Pengaruh Pemberian Pupuk Organik Terhadap Pertumbuhan Dan Hasil Tanaman Sawi Caisin (Brassica juncea L.). Agrobisnis, Vol.1, No. 1, Maret 2009.

PT. Nufarm Indonesia. 2016. Katalog produk. Jakarta (ID).

Simanjuntak, R. H., 1994. Bercocok Tanam Petsai. Bhratara. Jakarta

Udiarto. B.K. dan Setiawati W. 2007. Suseptibilitas Dan Kuantifikasi Resistensi 4 Strain Plutella Xylostella L, Terhadap Beberapa Insektisida. J. Hort. 17(3): 277-284.

Winasa, I.W., S. Herlinda. 2003. Population Of Diamondback Moth, Plutella xylostella L. (Lepidoptera: Plutellidae), and Its Damage And Parasitoids On Brassicaceous Crops. Di dalam: Prosiding International Seminar on Organic Farming and Sustainable Agriculture in the Tropics and Subtropics. Palembang Oktober 8-9, 2003. 